\title{
A randomized controlled trial of telephone- mentoring with home-based walking preceding rehabilitation in COPD
}

This article was published in the following Dove Press journal:

International Journal of COPD

25 August 2016

Number of times this article has been viewed

\section{Helen Laura Cameron- \\ Tucker' \\ Richard Wood-Baker' \\ Lyn Joseph' \\ Julia A Walters' \\ Natalie Schüz ${ }^{2}$ \\ E Haydn Walters'}

'Centre of Research Excellence for Chronic Respiratory Disease and Lung Aging, School of Medicine, ${ }^{2}$ School of Health Sciences, Faculty of Health, University of Tasmania, Hobart, Tasmania, Australia
Correspondence: Helen Laura

Cameron-Tucker

School of Medicine, University of

Tasmania, Medical Science I Building,

17 Liverpool Street, Private Bag 23,

Hobart, Tasmania 7000, Australia

$\mathrm{Tel}+6 \mathrm{I} 362264893$

Fax +6I 362267704

Email cameronh@utas.edu.au
Purpose: With the limited reach of pulmonary rehabilitation (PR) and low levels of daily physical activity in chronic obstructive pulmonary disease (COPD), a need exists to increase daily exercise. This study evaluated telephone health-mentoring targeting home-based walking (tele-rehab) compared to usual waiting time (usual care) followed by group PR.

Patients and methods: People with COPD were randomized to tele-rehab (intervention) or usual care (controls). Tele-rehab delivered by trained nurse health-mentors supported participants' home-based walking over 8-12 weeks. PR, delivered to both groups simultaneously, included 8 weeks of once-weekly education and self-management skills, with separate supervised exercise. Data were collected at three time-points: baseline (TP1), before (TP2), and after (TP3) PR. The primary outcome was change in physical capacity measured by 6 -minute walk distance (6MWD) with two tests performed at each time-point. Secondary outcomes included changes in self-reported home-based walking, health-related quality of life, and health behaviors.

Results: Of 65 recruits, 25 withdrew before completing PR. Forty attended a median of 6 (4) education sessions. Seventeen attended supervised exercise ( $5 \pm 2$ sessions). Between TP1 and TP2, there was a statistically significant increase in the median 6MWD of 12 (39.1) $\mathrm{m}$ in controls, but no change in the tele-rehab group. There were no significant changes in 6MWD between other time-points or groups, or significant change in any secondary outcomes. Participants attending supervised exercise showed a nonsignificant improvement in 6MWD, 12.3 (71) m, while others showed no change, 0 (33) m. The mean 6MWD was significantly greater, but not clinically meaningful, for the second test compared to the first at all time-points.

Conclusion: Telephone-mentoring for home-based walking demonstrated no benefit to exercise capacity. Two 6-minute walking tests at each time-point may not be necessary. Supervised exercise seems essential in PR. The challenge of incorporating exercise into daily life in COPD is substantial.

Keywords: pulmonary rehabilitation, physical capacity, self-reported walking, structured selfmanagement-based education, exercise

\section{Introduction}

Chronic obstructive pulmonary disease (COPD) is a progressive respiratory condition with systemic effect, ${ }^{1}$ exacting a substantial burden of increasing breathlessness and physical restrictions on individuals. ${ }^{2}$ This is of concern, as more physically active people with COPD have a lower risk of hospitalization and all-cause mortality ${ }^{3}$ and these individuals experience better physiologic function. ${ }^{4}$

Pulmonary rehabilitation (PR) is an intervention shown to help people with COPD improve their physical and psychosocial health, and is advocated as an integral 
component of COPD management. ${ }^{5,6}$ Supervised exercise is regarded as a key component of PR. Those who participate in conventional PR can expect an improvement in their physical capacity, health-related quality of life, breathlessness, and fatigue. ${ }^{7}$ However, the effect on daily physical activity levels in the community has only recently been investigated and appears to be minimal. ${ }^{8}$

The Australian Government defines "physical activity" as skeletal bodily movement resulting in ongoing health benefits, and "exercise" as a subset of physical activity, purposefully planned to maintain or improve physical health. ${ }^{9}$ "Physical capacity" refers to a person's overall ability to function and "undertake the physically demanding activities of daily living". ${ }^{10}$ These distinctions are important. One major outcome of PR is an improvement in physical capacity. While this may correlate with daily physical activity, ${ }^{11}$ formal physical capacity measures alone cannot reveal whether an individual is meeting recommended physical activity guidelines for health. Indeed, the literature indicates that people with COPD are predominantly sedentary, ${ }^{12}$ with exercise guidelines not being met. ${ }^{11}$

Despite the benefits of $\mathrm{PR}$, its reach is limited. Internationally $\sim 1 \%$ of people with COPD have access to PR. ${ }^{13}$ Australian data reflect this, with 200 programs available nationwide, predominantly based in health care facilities and accessed by only $1 \%$ of those who might benefit. ${ }^{14}$ Others have sought to increase the reach of interventions for people with COPD with promising technologies, such as brief telephone support, ${ }^{15}$ mobile telephone programs, ${ }^{16}$ or the computer-based Nintendo Wii Fit. ${ }^{17}$ Similarly, weekly reported diary-recorded home-walking has increased physical capacity compared to usual care. ${ }^{18}$

Strategies that foster self-management for sustained behavior change via telephone health-mentoring have been investigated. ${ }^{19,20}$ Self-management is
a process that facilitates an individual's confidence and capability to engage in health-promoting behaviors in order to deal with the impact of their condition on all aspects of their health-namely, a sense of self, physical, emotional, social and medical domains so as to maximize function and quality of life. ${ }^{21}$

Working with people to develop self-management skills is recognized as integral to $\mathrm{PR}^{6}$ and could even be an alternative to formal supervised exercise sessions.

Telephone health-mentoring trials to improve selfmanagement in COPD using community nurses improved health-related quality of life ${ }^{20}$ and self-management capacity. ${ }^{19}$ However, the effect on physical capacity or physical activity was not examined, which is important given the increasing focus on physical activity in COPD. ${ }^{22,23}$

One self-management approach that has reported improvements in self-reported physical activity is the group-based Stanford Chronic Disease Self-Management Program (CDSMP). ${ }^{24}$ We recently investigated the addition of an hour of supervised exercise to the CDSMP for people with COPD in a randomized controlled clinical trial, finding a small statistically significant increase in physical capacity. ${ }^{21}$ However, the increase of $20 \mathrm{~m}$ was less than half that reported in a review of traditional $\mathrm{PR}^{7}$ and less than the accepted minimal clinical important difference reported by others. ${ }^{25,26} \mathrm{We}$ found no difference between the intervention and control groups for self-reported physical activity.

To better meet clinical demand for PR, augmenting the gains we observed in the $\mathrm{CDSMP}^{21}$ and with telephone-based self-management support in COPD ${ }^{19,20}$ hold promise. In this study, we investigated the effects of telephone-based healthmentoring (tele-rehab) targeting home-based walking on physical capacity and self-reported physical activity.

\section{Materials and methods Study design}

This parallel-group randomized clinical trial in COPD aimed to evaluate the effectiveness of tele-rehab followed by PR versus usual care, that is, a waiting period followed by the same PR. The primary outcome was physical capacity measured by the 6-minute walk distance (6MWD). ${ }^{27}$

The minimally important clinical difference (MICD) for the 6MWD at the time of our study was $35 \mathrm{~m}(95 \%$ confidence interval 30-42 m). ${ }^{28}$ In a recent study, we found the standard deviation of the change in distance walked was $46.2 \mathrm{~m}^{21}$ and the attrition rate in our rehabilitation program was $33 \%$. Using these data, we calculated that the study would need to recruit 37 participants in each arm (power $=0.8$, significance $=0.05$ ) to demonstrate potential superiority of the intervention.

Participants were assigned a unique identification number and randomized to the tele-rehab (intervention) or to usual care (control) group using computer-generated random numbers by a research assistant not associated with the study, ensuring neutral allocation after baseline data collection. The trial was registered with the Australian and New Zealand Clinical Trials Registry (ACTRN12611001034921).

\section{Study subjects}

Following a hospital admission or clinic visit, adults with COPD, who were referred for PR at the Royal Hobart Hospital, a tertiary, university-affiliated public hospital, were 
screened and recruited. Referring staff were aware that this study was taking place.

Individuals were included in the study if they were over 18 years of age, had spirometry-diagnosed COPD, and were at least 2 months post an exacerbation prior to data collection. They were excluded if they experienced cognitive impairment, were unable to provide informed consent, could not complete questionnaires independently, did not meet safety to exercise criteria, ${ }^{29}$ or had attended some form of PR in the previous 2 years. For those people not wishing to participate in the project or who did not meet the inclusion criteria, follow-up management, including referral to a physiotherapist or PR, was offered in the course of usual care.

\section{Detail of interventions}

Screening of initial referrals confirming general study suitability (age, diagnosis, comorbidities) was followed by a telephone invitation to attend an appointment. Following informed consent, inclusion criteria were confirmed, and baseline data collected (time-point 1, TP1). The next data collection was at 8 to 12 weeks, after either tele-rehab or the usual waiting time (time-point 2, TP2), and the final data collection was after 8 weeks of PR (time-point 3, TP3).

Tele-rehab aimed to specifically support participants in undertaking exercise as well as address other mutually identified health behaviors from smoking, nutrition, alcohol consumption, physical activity, psychosocial well-being, and symptom management (“SNAPPS"). ${ }^{30,31}$ Following randomization, participants in the intervention group completed a summary of their SNAPPS health behaviors with the research officer and established a home-based walking plan, aiming to meet Australian guidelines at the time of the study: to walk at a moderate intensity (ie, to breathe more heavily but not to "huff and puff") to accumulate 30 minutes daily on several and preferably all days of the week. ${ }^{32}$ They received a copy of their written personal walking action plan, their personal SNAPPS summary, plus information concerning health behaviors (Supplementary material). Participants were contacted via telephone by specifically trained community nurses ${ }^{19,20,33}$ who acted as nurse health-mentors over the next 8-12 weeks, to support the home-walking action plan and any other health behavior plans. A schedule of two calls weekly was suggested, with a minimum of four calls mutually agreed with each participant, based on findings in a previous study that indicated participants preferred a flexible schedule for health-mentoring contacts. ${ }^{20}$

Participants in usual care waited for 8 to 12 weeks prior to their scheduled PR appointment without any additional contact, reflecting the Australian context of PR. ${ }^{34}$
At the time of this study, the local Tasmanian waiting time was $>3$ months.

PR followed the format of our previous study, consisting of 1 hour, once-weekly of 8 weeks of structured group education with self-management skills development (the CDSMP) and 1 hour of gym-based weekly supervised exercise. ${ }^{21}$ Supervised exercise was delivered in the same week but on a subsequent day to the education sessions. Individualized programs of aerobic exercise (aiming for at least 30 minutes of bicycle or treadmill exercise) with strengthening and stretching at a moderate to strong intensity determined and monitored by self-reported perception of exertion were developed. A discussion session targeting exercise and physical activity was offered with the education sessions. Participants reported back at the commencement of each session on their diary-recorded home-walking plans set the previous week.

Participants and community nurses gave written, informed consent. The Tasmanian Human Research Ethics Committee granted ethical approval (H0011764).

\section{Outcome measures and data analyses}

Outcome measurements were blinded. The primary outcome was change in physical capacity, measured by the $6 \mathrm{MWD},{ }^{27}$ conducted according to standard Australian protocols. Two tests were performed at each time-point, with the longest distance of the two being recorded. ${ }^{35}$ Secondary outcomes are described in Table 1. Data pertaining to self-reported physical activity are presented as: 1) data from the SNAPPS snapshot

Table I Outcomes and measures

\begin{tabular}{|c|c|}
\hline Outcomes & Measures \\
\hline \multicolumn{2}{|l|}{ Primary outcome } \\
\hline Physical capacity & 6MWD, a field walking test ${ }^{27}$ \\
\hline \multicolumn{2}{|c|}{ Secondary outcomes } \\
\hline $\begin{array}{l}\text { Health-related } \\
\text { quality of life }\end{array}$ & CAT $(0-40,0=\text { best })^{48}$ \\
\hline Health behaviors & $\begin{array}{l}\text { "SNAPPS" snapshot questionnaire (total score } \\
0-60,60=\text { best; domain score } 0-10,10=\text { best) }\end{array}$ \\
\hline Physical activity $(\mathrm{I})$ & $\begin{array}{l}\text { Self-reported walking (retrospective report) from } \\
\text { SNAPPS snapshot questionnaire, } \\
\text { Physical activity domain: } \\
\text { Days per week } \\
\text { Minutes per day }\end{array}$ \\
\hline Physical activity (2) & $\begin{array}{l}\text { Home-based walking action plan recorded in a } \\
\text { personal walking diary (self-recorded in real time) }\end{array}$ \\
\hline $\begin{array}{l}\text { but are not reported } \\
\text { measure of physical act } \\
\text { Abbreviations: } 6 \mathrm{MW} \\
\text { Test; COPD, chronic } \\
\text { alcohol consumption, }\end{array}$ & $\begin{array}{l}\text { to measure hospital admissions but there were insufficient } \\
\text { e collected regarding participant and mentor experiences } \\
\text { ty. (I) =First measure of physical activity; (2) =second } \\
\text { 6-minute walk test distance; CAT, COPD Assessment } \\
\text { structive pulmonary disease; SNAPPS, smoking, nutrition, } \\
\text { hysical activity, psychosocial well-being, and symptom }\end{array}$ \\
\hline
\end{tabular}


questionnaire, that is, a retrospective report of habitual moderate intensity walking (how many days per week and minutes per day performed on average over the previous 4 weeks) and 2) data from the walking diary-recorded in real time during PR. The first measure reflects the usual enquiry about physical activity in our clinical practice.

Analysis was by intention-to-treat, missing data handled by last case carried forward, and comparisons made using Mann-Whitney $U$-tests, Student's $t$-tests, or chi-squared analyses. Correlations were investigated using Pearson's correlation coefficient. Significance was set at a $P$-value of $<0.05$. Blinding with respect to participant allocation was maintained until data analyses were complete.

\section{Results}

\section{Participants}

Recruiting took place over 15 months from February 2012 (Figure 1). Of the 362 individuals referred, most (73\%) were inpatients referred by the respiratory nurse specialist or physiotherapists, with $23 \%$ referred directly by respiratory physicians, $4 \%$ by general practitioners and community nurses, and $3 \%$ by other hospital ward-based doctors. Of the 297 not included in the study, nearly two-thirds declined an appointment, citing health or travel issues as the main barrier to attendance (Figure 1). Although we had planned to recruit 74 individuals, we made a decision to cease recruiting in order to complete the follow-up TP3 assessments as

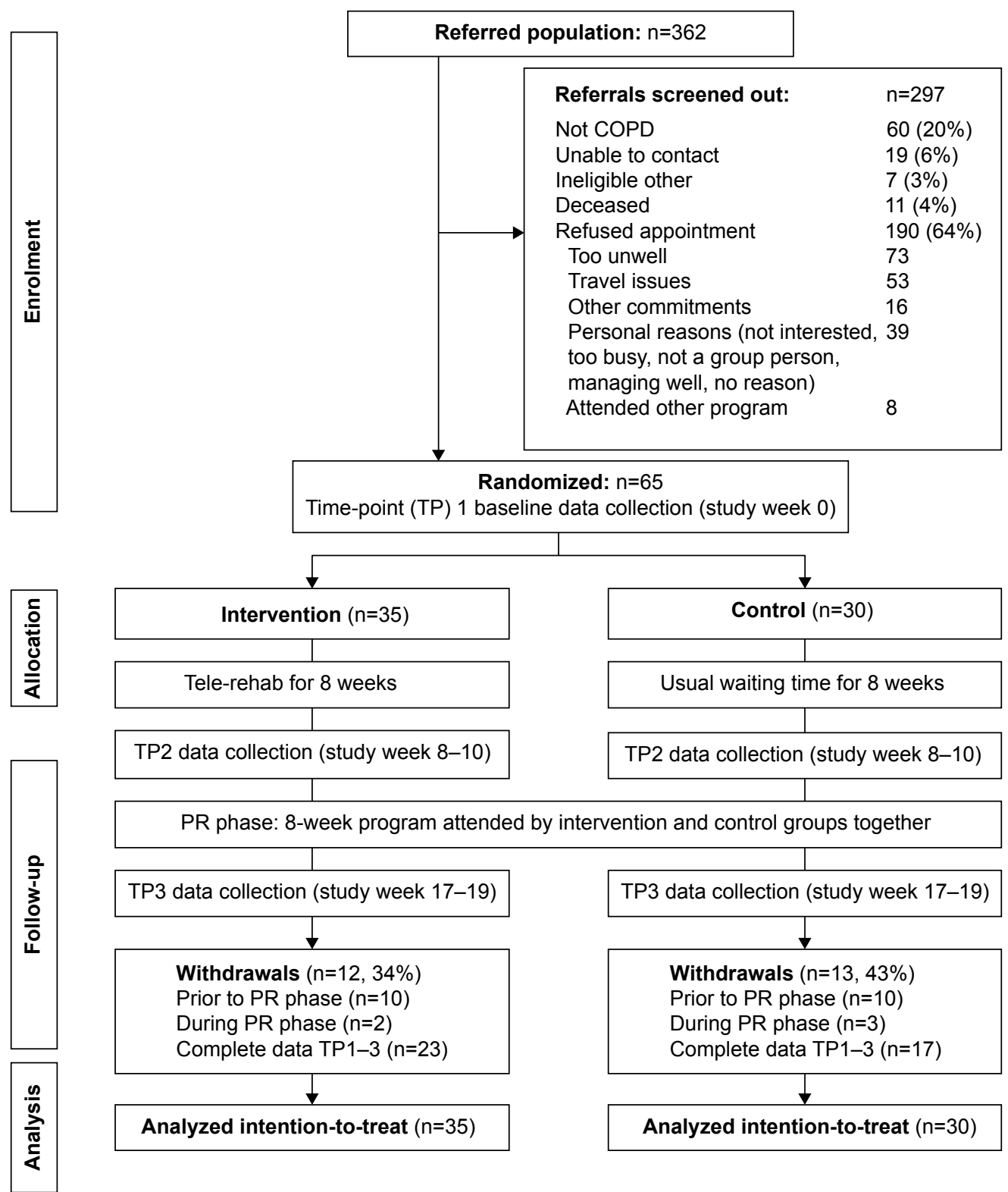

Figure I Flowchart depicting flow of participants through the study.

Abbreviations: COPD, chronic obstructive pulmonary disease; PR, pulmonary rehabilitation. 
scheduled. Thus, 65 participants were randomized, 35 to the intervention and 30 to the control groups, respectively. No participant changed groups during follow-up.

Of those 65 individuals randomized, 25 (38\%) withdrew (12 interventions and 13 controls) during the study, with males $(\mathrm{n}=17,68 \%)$ being more likely to withdraw than females $(P=0.005)$. The majority withdrew prior to PR commencing (ten in intervention and ten controls). "Ill health" was named by nearly half as the reason for withdrawing, time constraints by a quarter, with the remainder citing travel issues, giving no reason, or just failure to keep appointments.

Eighteen trained nurses delivered the mentoring for tele-rehab. There were a total of 231 telephone contacts, with a mean of $7 \pm 3$ calls per individual, each lasting a duration of $17 \pm 9$ minutes per call and $7 \pm 6$ days between calls. Contact with tele-rehab participants could not be made on 38 occasions and data were not recorded for 18 calls. Of 287 walking action plans set, $48 \%$ were completed, $27 \%$ not completed, and $25 \%$ not recorded. The principle reasons for not completing the walking program were being unwell or time constraints.

At the first PR session, only 31 (74\%) of the 42 participants remaining by this stage expressed intention to attend the supervised exercise sessions, despite all having consented to do so at recruitment. However, only 16 (38\%) actually commenced supervised exercise (ten in intervention and six controls), attending only a mean of $5 \pm 2$ sessions of a possible eight. A preference to exercise at home was stated as the main reason for not commencing supervised exercise, followed by travel issues. Of those who commenced supervised exercise, a greater proportion was female (75\%), did not have a partner (63\%), had moderate or severe COPD (82\%), and were in the intervention group (63\%). A median of 6 (4) sessions were attended, with ill health cited as the predominant reason for nonattendance.

At baseline, there were no statistically significant differences between the intervention and control group subjects for demographic (Table 2) or outcome (Table 3) measures, or between those who withdrew and those who completed all data collections.

\section{Primary outcome at different time-points}

There was a significant difference between groups for the change in the 6MWD over the first time period between TP1 and TP2, that is the effect of Tele-Rehab or usual waiting time (median 0 versus 12 meters, $P=0.01$ ). Counterintuitively, while there was no change in the active intervention group, there was an increase in the distance walked by controls (Table 4). There was no difference for the PR phase (Table 4). The 16 who attended supervised exercise did demonstrate a median increase of $12.3 \mathrm{~m}$ from PR but this was not statistically significant or clinically meaningful. Those not attending supervised exercise showed no change at all.

A statistically significant difference between the two walking tests was apparent at each time-point (Table 5). Approximately two-thirds of the group walked a small distance further on the second walking test.

Table 2 Participant characteristics

\begin{tabular}{|c|c|c|c|c|}
\hline Variable & $\begin{array}{l}\text { Participants } \\
(n=65)\end{array}$ & $\begin{array}{l}\text { Intervention } \\
(n=35)\end{array}$ & $\begin{array}{l}\text { Control } \\
(n=30)\end{array}$ & $\begin{array}{l}P \text {-value } \\
\text { (I versus C) }\end{array}$ \\
\hline Female & $36(55 \%)$ & $19(54 \%)$ & 17 (57\%) & 0.52 \\
\hline Age (years) & $69 \pm 8.6$ & $68 \pm 9.9$ & $70 \pm 6.8$ & 0.49 \\
\hline Married & $31(48 \%)$ & 19 & 12 & 0.18 \\
\hline Years of education & $10(3)$ & $10(3)$ & $10(3)$ & 0.99 \\
\hline \multicolumn{5}{|l|}{ Referral source } \\
\hline Physiotherapist, respiratory nurse (public hospital ward) & $37(57 \%)$ & $20(57 \%)$ & $17(57 \%)$ & \\
\hline Respiratory physicians (public and private practice) & $26(40 \%)$ & $13(37 \%)$ & $13(43 \%)$ & 0.40 \\
\hline Community (doctors, other) & $2(3 \%)$ & $2(6 \%)$ & 0 & \\
\hline Body mass index $\left(\mathrm{m}^{2} / \mathrm{kg}\right)$ & $27 \pm 6.8(n=63)$ & $27 \pm 5.9(n=34)$ & $28 \pm 7.7(n=29)$ & 0.48 \\
\hline \multicolumn{5}{|l|}{ COPD severity } \\
\hline Mild $\left(\mathrm{FEV}_{1}>80 \%\right)$ & $4(6 \%)$ & $3(9 \%)$ & I $(3 \%)$ & 0.46 \\
\hline Moderate (FEV, 59\%-79\%) & $22(34 \%)$ & $12(34 \%)$ & $10(33 \%)$ & \\
\hline Severe $(\mathrm{FEV}, 30 \%-49 \%)$ & $24(37 \%)$ & $10(29 \%)$ & 14 (47\%) & \\
\hline Very severe $(\mathrm{FEV},<30 \%)$ & $8(12 \%)$ & $6(17 \%)$ & $2(7 \%)$ & \\
\hline Missing data & 7 ( I I\%) & $4(\mathrm{I} / \%)$ & $3(10 \%)$ & \\
\hline
\end{tabular}

Notes: Data are reported as either mean \pm standard deviation, median (interquartile range), or raw number (percent) within study group status. The $P$-values are from Student's $t$-tests, Mann-Whitney $U$-tests, or chi-squared analyses. I = intervention, $C=$ control with a level of significance $P<0.05$. COPD severity classified according to GOLD classification.'

Abbreviations: COPD, chronic obstructive pulmonary disease; GOLD, Global Initiative for Chronic Obstructive Lung Disease; FEV ${ }_{1}$, forced expiratory volume in I second. 
Table 3 Baseline outcomes: intervention versus control group

\begin{tabular}{|c|c|c|c|}
\hline Variable & $\begin{array}{l}\text { Intervention } \\
\text { (tele-rehab + } \\
\text { PR phase) } \\
n=35\end{array}$ & $\begin{array}{l}\text { Control (usual } \\
\text { waiting time }+ \\
\text { PR phase) } \\
n=30\end{array}$ & P-value \\
\hline 6MWD (meters) & $333.3 \pm 120.9$ & $344.8 \pm 113.7$ & 0.69 \\
\hline CAT, scale $0-40$ & $22 \pm 6$ & $20 \pm 8$ & 0.27 \\
\hline $\begin{array}{l}\text { "SNAPPS" snapshot, } \\
\text { scale 0-60 }\end{array}$ & $\begin{array}{l}n=34 \\
38 \pm 7(n=34)\end{array}$ & $\begin{array}{l}n=29 \\
39 \pm 9(n=29)\end{array}$ & 0.78 \\
\hline \multicolumn{4}{|c|}{ SNAPPS snapshot domains scores, scale $0-10$} \\
\hline Smoking & $10(1)$ & $10(0)$ & 0.50 \\
\hline Nutrition & $9(5)$ & $8(7)$ & 0.27 \\
\hline Alcohol & $10(3)$ & $10(4)$ & 0.81 \\
\hline Physical activity & $5(8)$ & $0(8)$ & 0.40 \\
\hline Psychosocial & $5 \pm 2$ & $6 \pm 2$ & 0.13 \\
\hline $\begin{array}{l}\text { Symptom } \\
\text { management }\end{array}$ & $5(3)$ & $5(3)$ & 0.16 \\
\hline \multicolumn{4}{|c|}{ SNAPPS snapshot self-reported walking } \\
\hline Days per week & $3(5)$ & $0(4)$ & 0.20 \\
\hline Minutes per day & $10(30)$ & $3(23)$ & 0.62 \\
\hline
\end{tabular}

Notes: Data are reported as either mean \pm standard deviation or median (interquartile range). The $P$-values are from Student's $t$-tests or Mann-Whitney $U$-tests with a level of significance $P<0.05$ for the primary outcome.

Abbreviations: 6MWD, 6-minute walk distance; CAT, COPD assessment test; COPD, chronic obstructive pulmonary disease; PR, pulmonary rehabilitation; SNAPPS, smoking, nutrition, alcohol consumption, physical activity, psychosocial well-being, and symptom management.

\section{Secondary outcomes}

There were no statistically significant differences between the groups in any of the secondary outcomes (Table 4).

Walking diary data revealed no differences between groups in real-time reported walking (Table 6), although only 24 walking diaries were returned from a possible 40 .
Similarly, the average days walked per week and the average minutes per day during the PR phase were much the same for the two groups. Only nine participants recorded barriers to home-walking (being unwell or inclement weather), and seven cited facilitators (walking with another or incorporating exercise into daily activities).

Retrospectively reported walking (physical activity 1) showed a strong association with real-time recorded walking diary data (physical activity 2), with Pearson's correlation coefficients $(r)$ being 0.7 for days walked per week and 0.6 for minutes walked per day $(P=0.001$ and 0.002 , respectively).

\section{Discussion}

\section{Summary of results}

This study investigated extending the reach of PR by using tele-rehab to increase home-based walking for exercise.

We found no obvious objective improvement in the 6MWD for tele-rehab, or PR, with only controls demonstrating a very small and clinically nonmeaningful increase in 6MWD during the waiting period prior to PR. This is not easily explicable, and more likely represents measurement error, rather than a true effect. There were no changes in secondary outcomes.

Although walking diaries correlated well with selfreported exercise, no differences between the intervention or control groups or those who commenced supervised exercise and those who did not were found.

Table 4 Changes in outcomes between groups: intervention group versus control group

\begin{tabular}{|c|c|c|c|c|c|c|}
\hline \multirow[t]{4}{*}{ Variable } & \multirow{3}{*}{$\begin{array}{l}\text { Intervention } \\
\mathrm{n}=35 \text { (effect } \\
\text { of tele-rehab) }\end{array}$} & \multirow{3}{*}{$\begin{array}{l}\text { Control } \\
\mathrm{n}=30 \text { (effect of } \\
\text { usual waiting time) }\end{array}$} & \multirow[t]{4}{*}{$P$-value } & \multirow{3}{*}{$\begin{array}{l}\frac{\text { Intervention }}{\mathrm{n}=35 \text { (effect }} \\
\text { of tele-rehab) }\end{array}$} & \multirow{3}{*}{$\begin{array}{l}\text { Control } \\
n=30 \text { (effect } \\
\text { of PR phase) }\end{array}$} & \multirow[t]{3}{*}{$P$-value } \\
\hline & & & & & & \\
\hline & & & & & & \\
\hline & $\overline{\text { Change TPI/2 }}$ & Change TPI/2 & & $\overline{\text { Change TP2/3 }}$ & $\overline{\text { Change TP2/3 }}$ & \\
\hline \multicolumn{7}{|l|}{ Primary outcome } \\
\hline 6MWD (meters) & $0(4 I)$ & $12(39)$ & 0.01 & $0(23)$ & $0(19)$ & 0.51 \\
\hline \multicolumn{7}{|l|}{ Secondary outcomes } \\
\hline CAT, scale $0-40$ & $0(6)$ & $0(6)$ & 0.48 & $0(3)$ & $0(2)$ & 0.81 \\
\hline "SNAPPS" snapshot, scale 0-60 & $2(6)$ & I (4) & 0.42 & $0(5)$ & $0(4)$ & 0.70 \\
\hline \multicolumn{7}{|c|}{ SNAPPS snapshot domains, scale $0-10$} \\
\hline Smoking & $0(0)$ & $0(0)$ & 0.99 & $0(0)$ & $0(0)$ & 0.36 \\
\hline Nutrition & $0(0)$ & $0(0)$ & 0.989 & $0(0)$ & $0(0)$ & 1.00 \\
\hline Alcohol & $0(0)$ & $0(0)$ & 0.28 & $0(0)$ & $0(0)$ & 0.74 \\
\hline Physical activity & $0(4)$ & $0(4)$ & 0.4 & $0(1)$ & $0(0)$ & 0.80 \\
\hline Psychosocial & $0(0)$ & $0(0)$ & 0.737 & $0(0)$ & $0(0)$ & 0.47 \\
\hline Symptom management & $0(1)$ & $0(2)$ & 0.85 & $0(2)$ & $0(2)$ & 0.30 \\
\hline \multicolumn{7}{|c|}{ SNAPPS snapshot self-reported walking } \\
\hline Days per week & $0(5)$ & $0(0)$ & 0.64 & $0(1)$ & $0(1)$ & 0.81 \\
\hline Minutes per day & $14(26)$ & $16(40)$ & 0.10 & $16(23)$ & $17(29)$ & 0.96 \\
\hline
\end{tabular}

Notes: Data are reported as median (interquartile range). The $P$-values are from Mann-Whitney $U$-tests with a level of significance $P<0.05$. TPI/2=change between timepoint I and time-point 2, TP2/3= change between time-point 2 to time-point 3 . As there were no statistically or clinically significant changes between TPI and TP3, we report the effect of tele-rehab, usual waiting time, and PR phase.

Abbreviations: 6MWD, 6-minute walk distance; CAT, COPD assessment test; COPD, chronic obstructive pulmonary disease; PR, pulmonary rehabilitation; SNAPPS, smoking, nutrition, alcohol consumption, physical activity, psychosocial well-being, and symptom management. 
Table 5 Comparison of two 6-minute walk test distances conducted 30 minutes apart at different time-points

\begin{tabular}{|c|c|c|c|c|}
\hline $\begin{array}{l}\text { Time-point } \\
\text { (TP) }\end{array}$ & $\begin{array}{l}\text { Walk } \\
\text { distance I }\end{array}$ & $\begin{array}{l}\text { Walk } \\
\text { distance } 2\end{array}$ & $\begin{array}{l}\text { Change in } \\
\text { distance }\end{array}$ & $P$-value \\
\hline TPI & $318.2 \pm 116.4$ & $331.6 \pm 119.4$ & $13.5 \pm 4 \mid .0$ & 0.01 \\
\hline TP2 & $331.3 \pm 112.4$ & $346.4 \pm$ I I7.I & $15.2 \pm 28.0$ & $<0.001$ \\
\hline TP3 & $338.4 \pm$ III.5 & $346.8 \pm 117.0$ & $8.4 \pm 28.0$ & 0.02 \\
\hline
\end{tabular}

Notes: Data are reported as mean \pm standard deviation. The $P$-values are from Student's $t$-tests. Walk distance is measured in meters. Number of participants $=65$. Time-point I, baseline; time-point 2, after 8-12 weeks of tele-rehab or usual waiting time; time-point 3 , after 8 weeks of pulmonary rehabilitation phase.

Analyses of the 6MWD data from the two tests conducted at the three time-points revealed a statistically significant but not clinically meaningful increase in distance walked during the second test.

\section{MWD and physical activity}

We found limited evidence for the effectiveness of selfmanagement support via telephone health-mentoring on physical capacity or self-directed exercise at home. Others have similarly concluded that self-management focusing on education ${ }^{36}$ or self-management per se has minimal effect on physical capacity. ${ }^{37}$ Our data support the conclusions of the latter authors that this is due to participants not exercising at sufficient intensity and, as our results indicate, not walking at a sufficient frequency. In contrast, in a recent cohort study of home-based PR with once weekly supervision, participants exercised for at least 5 days per week, for 30 to 45 minutes, and at a higher intensity than our participants did, resulting in a statistically and clinically significant increase in physical capacity. ${ }^{38}$ Thus, a more demanding program, if enforceable, could have produced better outcomes.

It is possible that our tele-rehab intervention was not of sufficient duration or number of calls. A systematic review of telephone interventions for physical activity in adults, many with chronic conditions although not COPD, suggested that
12 or more calls over a 6-12-month period was effective in improving physical activity and dietary behavior. ${ }^{39}$ Our study fell short of this demanding schedule, being of only 2 months' duration with an average of seven calls per individual. Additionally, many of our participants did not complete their walking plans (27\%) because they were unwell. It may be that this strategy is just not feasible for those with moderate to severe COPD because of the degree of illness these people experience. Our data revealed a strong correlation between self-reported walking and diary-recorded walking, pointing to the validity of these questions routinely used in Australian physiotherapy clinical practice.

This study has also reinforced the conclusions drawn from our previous study: a mere hour of supervised exercise added to the CDSMP (the structured education component of our PR approach) does not result in clinically important changes in physical capacity or self-reported physical activity. ${ }^{21}$ This was exacerbated by the low attendance rate at supervised exercise offered separately to the education component in the clinical facility where the study took place. Despite emphasizing the importance of the supervised exercise sessions, compliance even with commencing was low (38\%), suggesting that participants may have perceived this to be an "optional extra". Attendance at exercise sessions may have been improved if this was seen to be a priority and if the importance of supervised exercise was reinforced by peers. ${ }^{40}$ It is obviously necessary that participants understand that attending higher intensity supervised exercise is paramount ${ }^{5,6}$ and without this they cannot expect to experience the benefits of PR. Our study supports the wider literature that supervised exercise is an essential component of PR, and it is likely that exercise sessions of substantial intensity, occurring at least twice per week, are needed to improve physical capacity. ${ }^{5,6}$

This study lends support to the presence of a learning effect for the 6MWD. ${ }^{41}$ The proportion of people walking further in our study was approximately two-thirds at each

Table 6 Walking diary data: intervention versus controls; exercise attendees versus nonattendees

\begin{tabular}{|c|c|c|c|c|c|c|}
\hline \multirow[t]{2}{*}{ Variable } & \multirow{2}{*}{$\begin{array}{l}\text { Intervention } \\
\text { (tele-rehab + } \\
\text { PR phase) } n=13\end{array}$} & \multirow{2}{*}{$\begin{array}{l}\text { Control (usual } \\
\text { waiting time }+ \\
\text { PR phase) } n=I \text { I }\end{array}$} & \multirow[t]{2}{*}{$P$-value } & \multicolumn{2}{|c|}{ Supervised exercise } & \multirow[t]{2}{*}{$P$-value } \\
\hline & & & & $\begin{array}{l}\text { Attendees, } \\
n=16\end{array}$ & $\begin{array}{l}\text { Nonattendees, } \\
n=49\end{array}$ & \\
\hline \multicolumn{7}{|c|}{ Week I, beginning of group-rehab } \\
\hline Days per week & $5(2)$ & $4(6)$ & 0.30 & $5(3)$ & $4(3)$ & 0.87 \\
\hline Minutes per day & $27(20)$ & $19(23)$ & 0.09 & $23(17)$ & $20(20)$ & 1.00 \\
\hline \multicolumn{7}{|c|}{ Average over 8 weeks of group-rehab } \\
\hline Days per week & $4 \pm 1$ & $4 \pm 1$ & 0.81 & $4 \pm 1$ & $4 \pm 1$ & 0.70 \\
\hline Minutes per day & $33 \pm 18$ & $29 \pm 8$ & 0.57 & $28 \pm 10$ & $34 \pm 18$ & 0.30 \\
\hline
\end{tabular}

Notes: Data are reported as either mean \pm standard deviation or median (interquartile range). The $P$-values are from Student's $t$-tests or Mann-Whitney $U$-tests with a level of significance $P<0.05$ for the primary outcome. As there was no statistically or clinically significant difference between the intervention or control groups, we have also reported data for those attending supervised exercise and those who did not.

Abbreviation: PR, pulmonary rehabilitation. 
of the three time-points, in contrast to the variability of $50 \%-87 \%$ reported in the Field Walking Tests Technical Standards. ${ }^{41}$ However, the increment was half that reported by others $^{42}$ and while statistically significant, it is less than half the MICD. ${ }^{28}$ Nevertheless, this small change may be important, for example, in a situation where reaching a threshold distance for 6MWD determines suitability for interventions. We would then concur with Holland et $\mathrm{al}^{41}$ that conducting two walking tests and recording the longest distance is recommended. However, if the MICD is to be the benchmark by which efficacy is measured and not 6MWD per se, our results suggest that a second test is not really required.

\section{Study limitations and implications for future practice and research}

There were some limitations to our study. First, despite community nurses being trained in core self-management support skills (motivational interviewing, ${ }^{43}$ problem-solving, ${ }^{44}$ action planning, ${ }^{45}$ and communication skills), we do not know the extent of fidelity to the intervention. Recording of telephone calls was an intent but proved to be logistically difficult in practice and was discontinued. If this is to happen in trials set in clinical practice, the equipment must be simple and quickly performed. Second, the tele-rehab intervention may have been better delivered by health professionals, such as physiotherapists who are skilled in the management of exercise, movement, and function for people with COPD. Additionally, individuals may require prior experience of structured exercise as well as integrating this into daily activities. ${ }^{38}$ Future research may indicate how many supervised sessions are initially required. Third, walking plans may need to be a combination of health professional prescription and self-set criteria, rather than wholly self-set as in the CDSMP paradigm that this study followed; "tough love" may be required. Fourth, while we did address barriers to exercise and physical activity as they arose, we did not investigate illness or exercise perceptions, that is, how people with COPD perceive their condition and their ability to exercise. Perceptions about exercise have been positively correlated with physical capacity ${ }^{46}$ and the same may hold true for illness perceptions and response to PR. This should be addressed prior to PR commencing, as should issues, such as anxiety and depression, which have now been shown to influence physical activity. ${ }^{47}$ Furthermore, it was not possible to recruit the number of individuals suggested by the a priori power analyses during the duration of the study. Therefore, nonparametric tests were used where possible. However, due to small cell sizes, results of chi-square tests may not be accurate. Future studies may want to replicate results with larger sample sizes.

\section{Conclusion}

In this small but insightful study, there was no benefit to a tele-rehab phase prior to group-based PR. Structured education with self-management skills development (the CDSMP), diary-recorded walking plans, and 1 hour of weekly supervised exercise added little. Two 6MWD tests may not always be necessary, despite a small learning effect. Supervised exercise is a mandatory component of PR. However, ongoing incorporation of exercise into daily life is also essential and there is a huge challenge to achieving this in people with COPD.

\section{Acknowledgments}

This work was supported in part by the Royal Hobart Hospital Research Foundation Grant, Hobart, Tasmania, Australia; a Department of Health and Human Services Grant, Hobart, Tasmania, Australia; and a University of Tasmania Research Enhancement Grant, Hobart, Tasmania, Australia. The authors would like to thank Physiotherapy Services, Royal Hobart Hospital, the Menzies Research Institute, Hobart, Tasmania, Australia, where this research took place and the research assistants Roxanne Maher, Carol Phillips, Helen de Hoog, Sharon Rees, and Emmie Bostock for their unfailing assistance. Finally, we are indebted to the community nurses and the people with COPD who willingly gave of their time and of themselves to participate in our research. An abstract pertaining to this paper was presented at the Thoracic Society of Australia and New Zealand Scientific Meeting, Adelaide, Australia, as a poster presentation with interim findings. The poster's abstract was published in "Poster Abstracts" (TP010, page 59) in (2014), Combined COPD/Cell Biology \& Immunology Sig Poster Presentation. Respirology, 19: 58-64. doi: 10.1111/resp.12263_2: http:// onlinelibrary.wiley.com/doi/10.1111/resp.12263 2/epdf

\section{Disclosure}

The authors report no conflicts of interest in this work.

\section{References}

1. Global Strategy for the Diagnosis Management and Prevention of COPD, Global Initiative for Chronic Obstructive Lung Disease (GOLD); 2013. Available from: http://www.goldcopd. Accessed June 21, 2013.

2. Williams V, Bruton A, Ellis-Hill C, McPherson K. What really matters to patients living with chronic obstructive pulmonary disease? An exploratory study. Chron Respir Dis. 2007;4(2):77-85.

3. Garcia-Aymerich J, Lange P, Benet M, Schnohr P, Antó JM. Regular physical activity reduces hospital admission and mortality in chronic obstructive pulmonary disease: a population based cohort study. Thorax. 2006;61(9):772-778. 
4. Garcia-Aymerich J, Serra I, Gómez FP, et al. Physical activity and clinical and functional status in COPD. Chest. 2009;136(1):62-70.

5. Bolton CE, Bevan-Smith EF, Blakey JD, et al. British Thoracic Society guideline on pulmonary rehabilitation in adults. Thorax. 2013; 68(Suppl 2):ii1-ii30.

6. Spruit MA, Singh SJ, Garvey C, et al. An official American Thoracic Society/European Respiratory Society statement: key concepts and advances in pulmonary rehabilitation. Am J Respir Crit Care Med. 2013; 188(8):e13-e64.

7. Lacasse Y, Goldstein R, Lasserson TJ, Martin S. Pulmonary rehabilitation for chronic obstructive pulmonary disease. Cochrane Database Syst Rev. 2006;18(4):CD003793. Available from: http://onlinelibrary. wiley.com/doi/10.1002/14651858.CD003793.pub2/abstract

8. Ng C, Whye L, Mackney J, Jenkins S, Hill K. Does exercise training change physical activity in people with COPD? A systematic review and meta-analysis. Chron Respir Dis. 2012;9(1):17-26.

9. Sims J, Hill K, Haralambous B, et al. National Physical Activity Recommendations for Older Australians: Discussion Document. Canberra: Australian Government Department of Health and Ageing; 2006.

10. Guyatt G, Thompson PJ, Berman BM, et al. How should we measure function in patients with chronic heart and lung disease? J Chron Dis. 1985;38:517-524.

11. Pitta F, Troosters T, Spruit MA, Probst VS, Decramer M, Gosselink R. Characteristics of physical activities in daily life in chronic obstructive pulmonary disease. Am J Respir Crit Care Med. 2005;171(9): 972-977.

12. Park SK, Richardson CR, Holleman RG, Larson JL. Physical activity in people with COPD, using the National Health and Nutrition Evaluation Survey dataset (2003-2006). Heart Lung. 2013;42(4):235-240.

13. Desveaux LI, Janaudis-Ferreira T, Goldstein R, Brooks D. An international comparison of pulmonary rehabilitation: a systematic review. COPD. 2015;12(2):144-153.

14. Australian Lung Foundation. A submission to The Health \& Hospital Reform Commission. Improving access to proven self-management therapies for effective chronic disease management. Pulmonary Rehabilitation: An Illustration. Lutwyche QLD 4030 2008; Available from: http://www.health.gov.au/internet/nhhrc/publishing.nsf/Content/039alf/\$FILE/039\%20-\%20SUBMISSION\%20-\%20Australian\%20 Lung\%20Foundation.pdf. Accessed August 11, 2014.

15. Wewel AR, Gellermann I, Schwertfeger I, Morfeld M, Magnussen H, Jörres RA. Intervention by phone calls raises domiciliary activity and exercise capacity in patients with severe COPD. Respir Med. 2008; 102(1):20-26

16. Liu WT, Wang $\mathrm{CH}$, Lin HC, et al. Efficacy of a cell phone-based exercise programme for COPD. Eur Respir J. 2008;32(3):651-659.

17. Albores J, Marolda C, Haggerty M, Gerstenhaber B, ZuWallack R. The use of a home exercise program based on a computer system in patients with chronic obstructive pulmonary disease. J Cardiopulm Rehabil Prev. 2013;33(1):47-52.

18. Singh V, Khandelwal DC, Khandelwal R, Abusaria S. Pulmonary rehabilitation in patients with chronic obstructive pulmonary disease. Indian J Chest Dis Allied Sci. 2003;45(1):13-17.

19. Walters J, Cameron-Tucker H, Wills K, et al. Effects of telephone health mentoring in community-recruited chronic obstructive pulmonary disease on self-management capacity, quality of life and psychological morbidity: a randomised controlled trial. BMJ Open. 2013;3(9):E003097.

20. Wood-Baker R, Robinson A, Reid D, Walters EH. Clinical trial of community nurse mentoring to improve self-management in patients with chronic obstructive pulmonary disease. Int J COPD. 2012;7:407-413.

21. Cameron-Tucker HL, Wood-Baker R, Owen C, Joseph L, Walters EH. Chronic disease self-management and exercise in COPD as pulmonary rehabilitation: a randomized controlled trial. Int $J$ COPD. 2014;9: 513-523.

22. Hartman JE, Boezen HM, De Greef MHG. Consequences of physical inactivity in chronic obstructive pulmonary disease. Expert Rev Respir Med. 2010;4(6):735-745.
23. Troosters T. Physical inactivity in patients with COPD: the next step is ... action. Prim Care Respir J. 2013;22(4):391-392.

24. Lorig KR, Sobel DS, Stewart AL, et al. Evidence suggesting that a chronic disease self-management program can improve health status while reducing hospitalization: a randomized trial. Med Care. 1999;37(1):5-14.

25. Holland A, Hill C, Rasekaba T, Lee A, Naughto M, McDonald C. Updating the minimal important difference for six-minute walk distance in patients with chronic obstructive pulmonary disease. Arch Phys Med Rehabil. 2010;91(2):221-225.

26. Puhan MA, Chandra D, Mosenifar Z, et al. The minimal important difference of exercise tests in severe COPD. Eur Respir J. 2011; 37(4):784-790.

27. Guyatt GH, Sullivan MJ, Thompson PJ, et al. The 6-minute walk: a new measure of exercise capacity in patients with chronic heart failure. Can Med Assoc J. 1985;132(8):919-923.

28. Puhan M, Mador M, Held U, Goldstein R, Guyatt G, Schunemann H. Interpretation of treatment changes in 6-minute walk distance in patients with COPD. Eur Respir J. 2008;32:637-643.

29. Balady GJ. American College of Sports Medicine ACSM's Guidelines for Exercise Testing and Prescription. 6th ed. Philadelphia, London: Lippincott Williams and Wilkins; 2000.

30. Department of Health and Human Services. Strengthening the Prevention and Management of Chronic Conditions. Policy Framework. Hobart; 2005.

31. Royal Australian College of General Practitioners. SNAP: a population health guide to behavioural risk factors in general practice; 2004 Available from: http://www.racgp.org.au/guidelines/greenbook. Accessed April 21, 2008.

32. Australian Government DoHaA. An Active Way to Better Health. National Physical Activity Guidelines. Canberra: Australian Government; 1999-2005.

33. Cameron-Tucker H, Joseph L, Walters J. Health self-management support training positively changes practice for nurses in primary care. Oral Session: O 002 Respirology. 2013;18(Suppl 2):10-37.

34. Australian Lung Foundation. Market Research Report. Pulmonary Rehabilitation Survey; 2007. Available from: http:/www.lungnet.com. au/copd/pr_pulmon_survey.html. Accessed September 29, 2007.

35. Alison Jea. The Pulmonary Rehabilitation Toolkit on behalf of The Australian Lung Foundation (2009); 2009. Available from: http:// lungfoundation.com.au/health-professionals/clinical-resources/copd/ pulmonary-rehabilitation-toolkit. Accessed October 17, 2014.

36. Blackstock FC, Webster KE, McDonald CF, Hill CJ. Comparable improvements achieved in chronic obstructive pulmonary disease through pulmonary rehabilitation with and without a structured educational intervention: a randomized controlled trial. Respirology. 2013; 19(2):193-202.

37. Zwerink M, Brusse-Keizer M, van der Valk Paul D, et al. Self management for patients with chronic obstructive pulmonary disease. Cochrane Database Syst Rev. 2014;19(3)CD002990. Available from: http://onlinelibrary.wiley.com/doi/10.1002/14651858.CD002990.pub3/ abstract

38. Grosbois JM, Gicquello A, Langlois C, et al. Long-term evaluation of home-based pulmonary rehabilitation in patients with COPD. Int $J$ Chron Obstruct Pulmon Dis. 2015;10:2037-2044.

39. Eakin EG, Lawler SP, Vandelanotte C, Owen N. Telephone interventions for physical activity and dietary behavior change: a systematic review. Am J Prev Med. 2007;32(5):419-434.

40. Moore L, Hogg L, White P. Acceptability and feasibility of pulmonary rehabilitation for COPD: a community qualitative study. Prim Care Respir J. 2012;21(4):419-424.

41. Holland AE, Spruit MA, Troosters T, et al. An official European Respiratory Society/American Thoracic Society technical standard: field walking tests in chronic respiratory disease. Eur Respir J. 2014;44(6): 1428-1446.

42. Hernandes NA, Wouters EFM, Meijer K, Annegarn J, Pitta F, Spruit MA. Reproducibility of 6-minute walking test in patients with COPD. Eur Respir J. 2011;38(2):261-267. 
43. Miller W, Rollnick S. Motivational Interviewing. New York: Guildford Press; 1991.

44. Warmerdam L, van Straten A, Cuijpers P. Internet-based treatment for adults with depressive symptoms: the protocol of a randomized controlled trial. BMC Psychiatry. 2007;7:72-78.

45. Leventhal H, Singer R, Jone S. Effects of fear and specificity of recommendation upon attitudes and behavior. J Pers Soc Psychol. 1965;2(1): 20-29.

46. Fischer MJ, Scharloo M, Abbink J, et al. Concerns about exercise are related to walk test results in pulmonary rehabilitation for patients with COPD. Int J Behav Med. 2012;19(1):39-47.
47. Schüz N, Walters J, Cameron-Tucker H, Scott J, Wood-Baker R, Walters H. Patient anxiety and depression moderate the effects of increased self-management knowledge on physical activity: a secondary analysis of a randomised controlled trial on health-mentoring in COPD. COPD. 2015;12:502-509.

48. Jones PW, Harding G, Berry P, Wiklund I, Chen WH, Kline Leidy N. Development and first validation of the COPD Assessment Test. Eur Respir J. 2009;34(3):648-654.

\section{Publish your work in this journal}

The International Journal of COPD is an international, peer-reviewed journal of therapeutics and pharmacology focusing on concise rapid reporting of clinical studies and reviews in COPD. Special focus is given to the pathophysiological processes underlying the disease, intervention programs, patient focused education, and self management protocols.

\section{Dovepress}

This journal is indexed on PubMed Central, MedLine and CAS. The manuscript management system is completely online and includes a very quick and fair peer-review system, which is all easy to use. Visit $\mathrm{http}: / / \mathrm{www}$. dovepress.com/testimonials.php to read real quotes from published authors.

\footnotetext{
Submit your manuscript here: http://www.dovepress.com/international-journal-of-chronic-obstructive-pulmonary-disease-journal
} 